\title{
Proteínas morfogenéticas ósseas associadas a osso esponjoso autógeno na reparação de falhas experimentais na calota craniana de coelhos (Oryctolagus cuniculus)
}

\author{
[Bone morphogenetic proteins associated with autogenous bone graft in the reparation of calvarial experimental \\ defects of rabbits (Oryctolagus cuniculus)]
}

\author{
B.S. Monteiro ${ }^{1}$, R.J. Del Carlo ${ }^{2}$, L.C.P. Pinheiro ${ }^{3}$, M.I.V. Viloria ${ }^{2}$, P.S.A. Silva ${ }^{1}$, \\ L.P.O. Souza ${ }^{3}$, P.Z. Balbinot ${ }^{1}$ \\ ${ }^{1}$ Aluno de pós-graduação - UFV - Viçosa, MG \\ ${ }^{2}$ Universidade Federal de Viçosa \\ Av. PH Rolfs, s/n \\ 36570-000 - Viçosa, MG. \\ ${ }^{3}$ Aluna de graduação - UFV - Viçosa, MG,
}

\begin{abstract}
RESUMO
Foi avaliada a reparação óssea após implantação de proteínas morfogenéticas ósseas (BMP) em diferentes concentrações e períodos de observação, carreadas por auto-enxerto ósseo esponjoso (EOE), em falhas ósseas, produzidas na região fronto-parietal do crânio de 20 coelhas. A falha I não foi preenchida, a II foi completamente preenchida com $3 \mathrm{mg}$ de EOE e as falhas III, IV, V e VI foram preenchidas com EOE associado a 0,$5 ; 1 ; 2$ e $5 \mathrm{mg}$ de BMP, respectivamente. Nas avaliações mesoscópicas, post mortem, verificou-se que, independentemente do período de tratamento, o preenchimento ósseo iniciou-se a partir das bordas para o centro e do fundo para a superfície das falhas. Na falha I manifestou-se o menor preenchimento ósseo quando comparada com as demais falhas, em todos os períodos, e nas que receberam $2 \mathrm{mg}$ de BMP exibiu-se a melhor cobertura óssea. Microscopicamente, verificou-se que, aos sete dias, o preenchimento ósseo iniciou-se a partir das bordas e do fundo da lesão, com mobilização e diferenciação de células provenientes do periósteo e das meninges, respectivamente e, nas avaliações subseqüentes, a atividade osteoblástica originou-se, também, de "ilhas de ossificação" semelhantes a centros de ossificação, localizadas no centro da falha. A formação trabecular aumentou, proporcionalmente, com a concentração utilizada de BMP, e a aposição e organização óssea aumentaram com o tempo de observação. Verificou-se também a presença de tecido cartilaginoso. A BMP associada ao EOE contribuiu para a formação de novo tecido ósseo, promovendo maior mobilização, diferenciação e organização celular, e abreviou o tempo de formação óssea, sugerindo processo de ossificação endocondral. Os melhores resultados foram observados com a associação de $2 \mathrm{mg}$ de BMP a $3 \mathrm{mg}$ de enxerto, e a adição de BMP, mesmo em menor quantidade, determinou precocidade de formação óssea. A maior quantidade de BMP não determinou maior preenchimento ósseo.
\end{abstract}

Palavras-chave: coelho, BMP, enxerto ósseo, reparação óssea

\begin{abstract}
Aspects of bone repair were evaluated after implantation of bone morphogenetic proteins (BMP) in different concentrations. They were carried by autogenous bone graft in defects created on skulls of 20 adult, young female rabbits, randomizedly divided into five experimental groups and were observed at five times. After exposure of skull bones, six bone defects on the fronto-parietal region of each animal were performed. The defect I was not filled, the II was completed filled with $3 \mathrm{mg}$ of autogenous bone graft and the defects III, IV, V, and VI were filled with autogenous bone graft associated with $0.5 ; 1 ; 2$
\end{abstract}

Recebido em 28 de março de 2006

Aceito em 17 de setembro de 2007

Autor para correspondência (corresponding author)

E-mail: ricarlo@ufv.br 
and $5 \mathrm{mg}$ of BMP, respectively. In the post-mortem mesoscopic evaluations, it was observed that, independently of the treatment period of the defects, the bony filling began from the borders to the center, and from the botton to the surface of the lessions. The bony filling of the defect I was the smallest when compared with the others defects, in all the observation moments. It was also verified that until $2 \mathrm{mg}$ the higher the concentration of BMP used, better was the bone cover. Microscopically, it was verified in the first evaluations, on the seventh day, that the bony growth started from the borders and from the bottom of the lesion, with mobilization and differentiation of cells deriving from the periosteum and the meninges, respectively. In the subsequent evaluations, the osteoblastic activity also derived from "ossification islands" to ossification centers, located in the center of the flaw. The trabecular formation increased proportionally with the concentration of BMP used, and the apposition and bony organization increased proportionally with the time of observation. The presence of cartilaginous tissue was verified in all the flaws. In conclusion, the use the higher concentration of BMP did not determinate the better new bone formation. The association of BMP with autogenous bone graft contributed to the formation of new bony tissue, promoting larger mobilization, differentiation, and cellular organization. It also shortened the time of bony formation, suggesting an endocondral ossification process. The better quantities relation was $3 \mathrm{mg}$ of autogenous bone graft and $2 \mathrm{mg}$ of BMP. The addiction of BMP, even so in low concentration, collaborated to early formation of new bone.

Keywords: rabbit, BMP, bone graft, bone repair

\section{INTRODUÇÃO}

Proteínas morfogenéticas ósseas (BMP) são proteínas não colágenas, presentes na matriz óssea, responsáveis pelo recrutamento celular e indução da diferenciação das células mesenquimais não diferenciadas em condroblastos e osteoblastos, produzindo novo tecido ósseo, in vivo e in vitro (Sommerman et al., 1983; Oleskovicz et al., 2004). Apresentam ação local, devendo ser depositadas diretamente no local de promoção do crescimento ósseo, e necessitam ser carreadas por agente que permita sua difusão por entre as células, facilitando a osteoindução (Marukawa et al., 2001; Ciani et al., 2006).

Tsumaki e Yoshikawa (2005) descreveram os eventos envolvidos na formação óssea induzida pelas BMP, entre eles quimiotaxia e proliferação de células mesenquimais, diferenciação em condroblastos e osteoblastos, calcificação da matriz cartilaginosa, angiogênese e invasão vascular, diferenciação, mineralização e remodelação ósseas, seguida de formação de medula óssea. Afirmaram que esses eventos são semelhantes aos que ocorrem num processo normal de ossificação endocondral, diferenciando-se apenas quanto ao estímulo à precocidade de formação.

Sato e Urist (1985) e Chelline et al. (2002) não evidenciaram relação de toxicidade após aplicação de BMP tanto em tecido muscular quanto em tecido ósseo. Observaram relação dose-dependente diretamente proporcional entre a quantidade de formação óssea e quantidade de proteína aplicada.

As proteínas morfogenéticas são rapidamente difusíveis e, para sua efetividade, precisam ser implantadas associadas a um carreador apropriado (Urist et al., 1983; Braz et al., 2003; Ciani et al. 2006) que deverá atuar como espaçador tridimensional, que fornece a estrutura necessária para a formação do novo tecido. Necessário, portanto, para manter o nível de concentração das BMP, e contê-las no local desejado (Rutherford et al., 1993; Kuboki et al., 1995).

O enxerto ósseo esponjoso (EOE) tem sido considerado um carreador ideal, atuando como arcabouço, ao promover a osteoindução e a vascularização precoce (Allegrini et al., 2004). Também, apresenta histocompatibilidade, fornece células osteogênicas e adapta-se às falhas ósseas existentes (Ellis e Sinn, 1993).

Após a aplicação do auto-enxerto de osso esponjoso a formação óssea inicia-se a partir de osteoblastos provenientes da medula, contida no interior de suas trabéculas, determinando formação osteóide direta, seguida de migração e diferenciação de células indiferenciadas, quimiotaticamente atraídas por fatores de crescimento presentes no enxerto. Todavia, a sua 
associação com BMP é um procedimento recente (Marx, 1994).

Este trabalho teve por objetivo analisar detalhes macro e microscópicos da reparação óssea e identificar a melhor relação entre a quantidade de BMP na reparação das falhas experimentais na calota craniana de coelhos.

\section{MATERIAL E MÉTODOS}

O experimento ${ }^{1}$ foi realizado em 20 coelhas da raça Nova Zelândia, com peso médio de $3,5 \mathrm{~kg}$ e idade entre seis e sete meses, mantidas em gaiolas individuais e alimentadas com ração comercial, feno e água.

À época dos procedimentos cirúrgicos, os animais foram mantidos em jejum sólido de oito horas e pré-anestesiados com acepromazina ${ }^{2}$ $(0,1 \mathrm{mg} / \mathrm{kg} / \mathrm{IV})$. Em seguida, foi realizada anestesia geral dissociativa de tiletamina/zolazepan ${ }^{3}$ (30mg/kg/IV) associados numa mesma seringa com $1 \mathrm{mg} / \mathrm{kg}$ de levomepromazina $^{4} \quad 0,5 \%$. Foram também submetidos à anestesia epidural com lidocaína ${ }^{5}$ $2 \%(0,9 \mathrm{ml} /$ animal $)$ para maior conforto durante a coleta do auto-enxerto ósseo na crista ilíaca.

A antibioticoterapia foi realizada com cinco aplicações de cefalexina ${ }^{6}(5 \mathrm{mg} / \mathrm{kg} / \mathrm{IM})$, uma após a indução anestésica e a cada 24 horas após o procedimento cirúrgico. A analgesia foi realizada com morfina ${ }^{7}(0,4 \mathrm{mg} / \mathrm{kg} / \mathrm{VO})$, no período préoperatório e a cada oito horas pós-cirurgia, durante três dias e, como medicação antiinflamatória, no pré-operatório foi utilizado cetoprofeno $^{8}(1,1 \mathrm{mg} / \mathrm{kg} / \mathrm{SC})$.

\footnotetext{
${ }^{1}$ Aprovado pela Comissão de Ética na Experimentação Animal, do Departamento de Veterinária - UFV, em 02/05 prot. $10 / 2005$.

${ }^{2}$ Acepram 1\% - Univet - São Paulo, Brasil

${ }^{3}$ Zoletil ${ }^{\circ}$ 50, Virbac - São Paulo, Brasil.

${ }^{4}$ Neozine $(5 \mathrm{mg} / \mathrm{ml})$ - Aventis Pharma - São Paulo, Brasil.

${ }^{5}$ Lidocaína 2\% - Anestésico Bravet - Rio de Janeiro, Brasil.

${ }^{6}$ Cefalexina $250 \mathrm{mg} / 5 \mathrm{ml}$ - Aventis Pharma - São Paulo, Brasil.

${ }^{7}$ Dimorf® Solução Oral - Cristália LTDA - Itapira, Brasil. ${ }^{8}$ Profenid IV (100mg/2ml) - Aventis Pharma - São Paulo, Brasil.
}

A BMP $^{9}$ utilizada apresentava-se como um produto liofilizado, e previamente ao procedimento cirúrgico, foi pesada em balança de precisão, nas quantidades pré-estabelecidas, para ser misturada ao enxerto esponjoso autógeno no momento do preenchimento das falhas ósseas.

Os animais foram posicionados em decúbito esternal, com a cabeça sobre uma almofada. Após preparo e anti-sepsia do campo cirúrgico foi realizada incisão de pele sobre a crista sagital externa do crânio, a partir da protuberância occipital e no sentido rostral, de aproximadamente $3 \mathrm{~cm}$ de comprimento. $\mathrm{O}$ tecido subcutâneo e os músculos frontal, interescutular, occipital e temporal foram incisados e rebatidos lateralmente, assim como o periósteo, permitindo a exposição do osso parietal.

Após a exposição dos ossos do crânio, com auxílio de uma broca trefina ${ }^{10}$ cirúrgica de $4,3 \mathrm{~mm}$ de diâmetro conectada a uma perfuratriz elétrica $^{11}$, na velocidade de 5000rpm e irrigação contínua com solução fisiológica (Fig. 1A), foram realizadas seis falhas ósseas na região fronto-parietal de cada animal, três no antímero direito e três no esquerdo, transpassando toda espessura óssea, com exposição e manutenção da integridade das meninges no fundo da falha.

Essas falhas encontravam-se afastadas por aproximadamente $8 \mathrm{~mm}$ e cada falha foi numerada de um a seis no sentido rostro-caudal, da direita para a esquerda (Fig. 1B). A falha I não foi preenchida e a falha II foi completamente preenchida com auto-EOE, na quantidade de $3 \mathrm{mg}$, ambas servindo como controle para avaliação do preenchimento ósseo. As falhas III, IV, V e VI foram preenchidas com o autoenxerto associado com 0,5; 1; 2 e $5 \mathrm{mg}$ de BMP, respectivamente.

O osso esponjoso autógeno foi coletado da crista ilíaca direita, após a realização das seis falhas. A cortical da crista ilíaca foi perfurada com uma broca de $5 \mathrm{~mm}$ conectada a uma parafusadeira manual de baixa rotação ${ }^{12}$, até a exposição do osso trabecular que, foi coletado com uma cureta

${ }^{9}$ Gen-Proß - Proteínas Morfogenéticas do Osso (BMP) -

BAUMER S.A - Mogi Mirim, Brasil.

${ }^{10}$ Neodent Implante Osteointegravel - Curitiba, Brasil.

${ }^{11}$ Microrretífica Dremel - Bosch - Rio de Janeiro, Brasil.

${ }^{12}$ Bosch 7,2 V - Rio de Janeiro, Brasil. 
oval ( $\left.\mathrm{n}^{\mathrm{o}} 1\right)$, pesado de forma asséptica, em balança de precisão e colocado sobre uma gaze umedecida com solução fisiológica até o momento da enxertia.

Ao término dos procedimentos, as fáscias musculares e a pele foram suturados de forma rotineira.

Após a cirurgia, os animais foram separados, aleatoriamente, em cinco grupos, constituídos de quatro animais (A, B, C e D) e, cada um desses grupos correspondeu ao tempo de observação e a uma época de eutanásia. No grupo 1 (G1) os animais foram observados por sete dias, no grupo 2 (G2) por 15 , no $3(\mathrm{G} 3)$ por 21 , no $4(\mathrm{G} 4)$ por 35 e no grupo 5 (G5) por 60 dias.

$\mathrm{Na}$ data prevista, os animais foram eutanasiados com sobredosagem anestésica, de tiobarbital sódico $^{13}$. A pele e a musculatura do crânio foram cuidadosamente removidas, permitindo a visualização do local operado e, com auxílio de uma serra manual, a região das falhas na porção fronto-parietal da calota craniana foi removida e submetida a exames mesoscópicos e processamento histológico.

A inspeção mesoscópica das falhas foi realizada a olho nu e sob lupa ${ }^{14}$, em aumento de até 50 vezes. Foram observadas as características dos tecidos presentes na falha e a intensidade do preenchimento ósseo em profundidade e largura e essa intensidade foi graduada com o auxílio de um paquímetro e classificada em escores, préestabelecidos: escore 0 para falhas não preenchidas; falhas com preenchimento ósseo inferior a $25 \%$ da área receberam escore 1 ; com preenchimento da área entre 25 a $50 \%$ escore 2 ; entre 50 a $75 \%$ escore 3 ; entre 75 a $95 \%$ escore 4; preenchimento em quase toda extensão, mas não em $100 \%$ da área receberam escore $5 \mathrm{e}$ falhas totalmente preenchidas, escore 6 .

Em cada grupo foram estabelecidas as médias do grau de preenchimento ósseo dos quatro animais para cada tipo de tratamento realizado nas falhas. Os valores médios encontrados foram comparados e analisados entre as demais falhas dentro do mesmo grupo experimental pelo

\footnotetext{
${ }^{13}$ Tiopental sódico - Cristália Ltda - Itapira, Brasil.

${ }^{14}$ Microscópio Estereoscópico - Stemi SV6 - Zeiss - São Paulo, Brasil.
}

modelo não paramétrico Kruskall-Wallis a 5\% de significância, pelo programa BioEstat 2.0 (Ayres et al., 2000). Após a determinação da diferença estatística entre os tratamentos, eles foram comparados dois a dois. Os valores médios foram também comparados qualitativamente entre os diferentes grupos experimentais.

O material proveniente da região da falha associado ao osso receptor adjacente foi fixado por 48 horas em formalina $10 \%$ tamponada e processado de forma rotineira para tecidos ósseos. Cortes sagitais de $5 \mu \mathrm{m}$ de espessura, da porção medial/central da falha, que envolviam o osso receptor nas bordas, foram corados com hematoxilina e eosina (HE) e com tricromo de Masson e avaliados quanto à morfologia e organização celular e ao tipo de tecido reparava as falhas. Para a aquisição das imagens fotográficas, utilizou-se câmara digital ${ }^{15}$ acoplada a microscópio óptico binocular ${ }^{16}$, fazendo a captura das fotografias pelo programa Photograb Fujifilm 300Z. Foram realizadas análises descritivas dos achados histológicos.

\section{RESULTADOS E DISCUSSÃO}

Apesar da exposição das meninges na confecção das falhas, durante o período pós-operatório não foram observados sinais de infecção ou complicações neurológicas e todas as coelhas permaneceram alertas, conscientes e deambulando normalmente. $\mathrm{O}$ modelo experimental utilizado destaca-se pela baixa capacidade regenerativa dos ossos do crânio, e permite avaliar alternativas reconstrutivas com agentes que estimulam a reparação, uma vez que implantes sintéticos podem provocar desconforto ao paciente e o auto-enxerto ósseo, quando usado isoladamente, corre o risco de ser reabsorvido antes que a reparação se processe por completo, segundo Del Carlo et al. (1994) e Braz et al. (2003).

As concentrações de BMP utilizadas estavam dentro dos limites de toxicidade estabelecidos como seguros para leporídeos por Sato e Urist (1985) e Chelline et al. (2002). Na literatura consultada, observa-se grande variação de concentrações que se deve ao número de modelos experimentais, às diversas espécies animais utilizadas e aos diferentes tipos de BMP existentes.

\footnotetext{
${ }^{15}$ Nikon HC 300 Zi - São Paulo, Brasil

${ }^{16}$ Microscópio Óptico Nikon Eclipse E600 - Califórnia, EUA.
} 


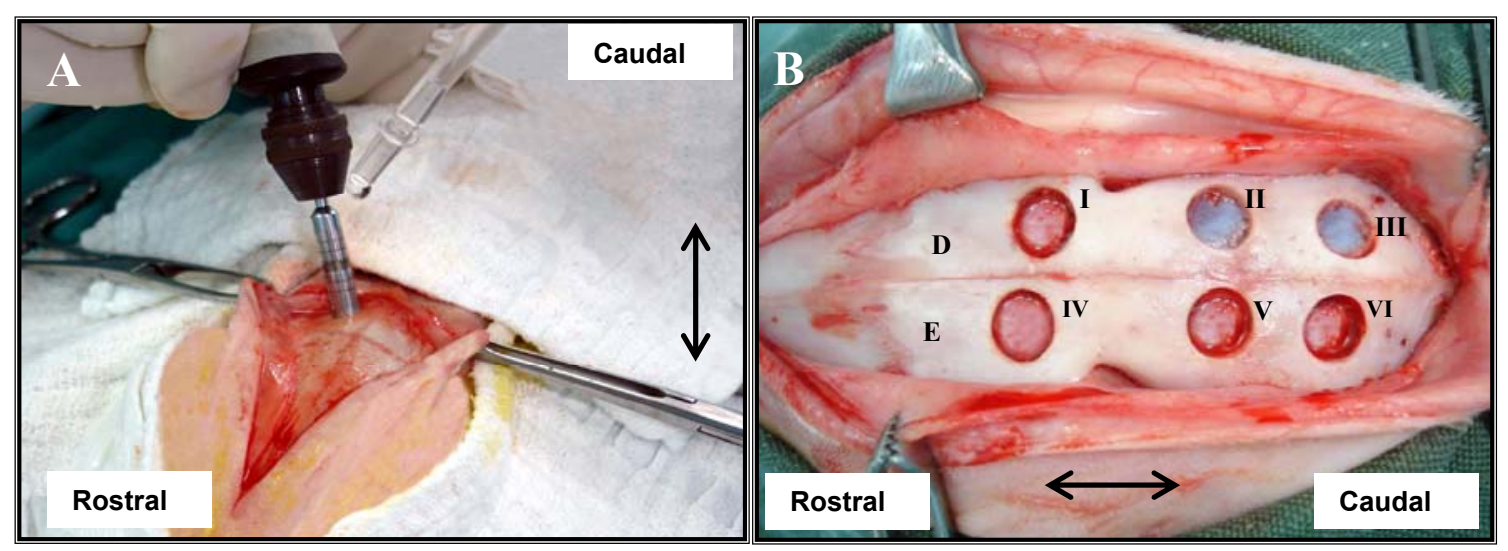

Figura 1. Procedimentos cirúrgicos realizados no osso fronto-parietal dos coelhos. A) confecção da falha com broca trefina sob irrigação com solução fisiológica. B) numeração das falhas ósseas de I a VI no sentido rostro-caudal, da direita (D) para a esquerda (E).

$\mathrm{Na}$ avaliação mesoscópica, post mortem, em todas as falhas dos 20 animais, observou-se tecido de aspecto fibroso na região de sutura das fáscias musculares. A presença de coágulo, no interior e sobre a falha-controle, foi verificada em todos os animais do G1 (sete dias) e em dois animais do G2 (15 dias). O coágulo foi substituído gradativamente nas avaliações subseqüentes, caracterizando evolução do processo de reparação, em que o coágulo inicialmente tampona a lesão e é substituído por fibroblastos e células osteogênicas.

Ainda, mesoscopicamente, não foi observado crescimento ósseo na face ventral das meninges, em contato com o tecido nervoso. Independentemente do período de observação e do tratamento, o preenchimento iniciou-se a partir das bordas para o centro (centrípeto) e do fundo para a superfície das falhas, apresentando aspecto menos compacto que o tecido ósseo vizinho, típico de tecido osteóide, semelhante ao descrito por Sato e Urist (1985), provavelmente pela precocidade da observação e imaturidade do tecido ósseo formado.

O preenchimento ósseo à inspeção mesoscópica, em profundidade e largura, verificado em cada uma das falhas dos animais, nos diferentes períodos de observação, é apresentado na Tab. 1.

Houve diferença significativa $(\mathrm{P} \leq 0,05)$ entre os tratamentos realizados. Quanto ao preenchimento ósseo exibido pelas falhas I e II não houve diferença entre tratamentos em nenhum momento de avaliação, porém foram menores que os encontrados nas falhas tratadas.

Nas falhas V e IV exibiram-se maiores valores de preenchimento ósseo em todos os grupos experimentais, o que demonstrou o melhor preenchimento ósseo e permitiu inferir que a reparação óssea aumentou na presença de BMP carreada por enxerto esponjoso, confirmando, assim, os resultados encontrados por Chang et al. (2004). Aos 15 dias (G2), essa diferença entre os tratamentos era mais evidente $(\mathrm{P}=0,0003)$, sobretudo ao se compararem as falhas I e II àquelas que receberam BMP.

Resultados semelhantes ao do G2 foram encontrados no $\mathrm{G} 1(\mathrm{P}=0,0006)$. Para os grupos 3,4 e 5, na comparação entre os tratamentos com BMP, não houve diferença, as diferenças foram apenas para as falhas que não receberam BPM. Tais fatos confirmam os resultados obtidos por Sakou (1998) e Wan e Cao (2005) que verificaram que as BMP atuam na precocidade da formação óssea, pois imediatamente após a ligação dessas proteínas a seus receptores, elas desencadeiam suas atividades moleculares e fosforilação de proteínas que ativam as células osteogênicas. Com o passar do tempo, as mudanças moleculares desencadeadas cessam e, como não há mais receptores a serem ativados nem BMP exógena, apenas o turn over ósseo estimulou a formação subseqüente. 
Tabela 1. Classificação em escores, para o grau de preenchimento ósseo ao exame mesoscópico da calota craniana de todos os coelhos, apresentado por cada falha óssea, em todos os períodos de observação

\begin{tabular}{|c|c|c|c|c|c|c|c|}
\hline \multirow{2}{*}{ Grupo } & \multirow{2}{*}{ Animal } & \multicolumn{6}{|c|}{ Preenchimento ósseo das falhas ósseas experimentalmente criadas (escores) } \\
\hline & & Falha I & Falha II & Falha III & Falha IV & Falha V & Falha VI \\
\hline & A & 1 & 2 & 3 & 3 & 5 & 3 \\
\hline 1 & B & 1 & 2 & 3 & 3 & 3 & 3 \\
\hline \multirow[t]{3}{*}{ (sete dias) } & $\mathrm{C}$ & 1 & 2 & 3 & 3 & 3 & 3 \\
\hline & D & 1 & 2 & 3 & 3 & 3 & 3 \\
\hline & $\mathrm{A}$ & 1 & 3 & 4 & 4 & 5 & 4 \\
\hline 2 & B & 1 & 3 & 4 & 4 & 5 & 4 \\
\hline \multirow[t]{3}{*}{ (15 dias) } & $\mathrm{C}$ & 1 & 3 & 4 & 4 & 5 & 4 \\
\hline & D & 1 & 3 & 4 & 4 & 5 & 4 \\
\hline & A & 2 & 3 & 3 & 4 & 5 & 4 \\
\hline 3 & B & 2 & 3 & 3 & 3 & 4 & 4 \\
\hline \multirow[t]{3}{*}{ (21 dias) } & $\mathrm{C}$ & 1 & 3 & 5 & 2 & 5 & 1 \\
\hline & $\mathrm{D}$ & 1 & 3 & 4 & 5 & 4 & 3 \\
\hline & A & 1 & 5 & 3 & 4 & 4 & 4 \\
\hline 4 & B & 2 & 3 & 4 & 4 & 5 & 2 \\
\hline \multirow[t]{3}{*}{ (35 dias) } & $\mathrm{C}$ & 2 & 3 & 3 & 4 & 5 & 1 \\
\hline & D & 2 & 3 & 4 & 4 & 5 & 4 \\
\hline & A & 3 & 3 & 4 & 4 & 5 & 4 \\
\hline \multirow{3}{*}{$\begin{array}{c}5 \\
(60 \text { dias })\end{array}$} & B & 2 & 4 & 4 & 5 & 5 & 3 \\
\hline & $\mathrm{C}$ & 2 & 4 & 4 & 4 & 5 & 4 \\
\hline & D & 3 & 4 & 4 & 4 & 4 & 3 \\
\hline
\end{tabular}

Falhas não preenchidas: escore 0; falhas com preenchimento ósseo inferior a $25 \%$ : escore 1; falhas com preenchimento entre 25 a $50 \%$ : escore 2; falhas com preenchimento entre 50 a $75 \%$ : escore 3; falhas com preenchimento entre 75 a $95 \%$ escore 4 ; falhas com preenchimento em quase toda extensão, mas não em $100 \%$ da área: escore 5; falhas totalmente preenchidas: escore 6.

Sato e Urist (1985) observaram que a porcentagem de preenchimento da falha óssea se deu em função da dose utilizada de BMP e do tempo de observação, fato também verificado neste estudo. Outro achado semelhante foi a superioridade de preenchimento ósseo nas falhas que receberam BMP em relação às falhascontrole, independentemente da concentração utilizada, em todos os períodos de observação.

A quantidade de osso novo nas falhas que continham as BMP associadas ao auto-enxerto esponjoso foi maior que a encontrada nas falhascontrole e nas que continham apenas o enxerto, o que evidencia a capacidade desse enxerto como carreador ideal para BMP, nas condições deste experimento, assim como já havia sido relatado em diferentes situações por Becker et al. (1995), Piattelli et al. (1998) e Allegrini et al. (2004). Também é possível inferir que ele permitiu a atividade osteoindutora da proteína óssea morfogenética.
De acordo com Yasko et al. (1992), Cook et al. (1994) e Chelline et al. (2002), a ação da BMP é dose-dependente. Da mesma forma, foi observado que até os valores de $2,0 \mathrm{mg}$, quanto maior a quantidade das BMP utilizadas, maior foi o preenchimento, já que as falhas $\mathrm{V}$ foram as que apresentaram maior cobertura óssea. Todavia, a maior quantidade utilizada não determinou o maior preenchimento ósseo, podendo-se inferir que a quantidade de enxerto utilizada como carreador não forneceu arcabouço e osteogenicidade proporcionais à quantidade de BMP, limitando a atividade desta proteína.

$\mathrm{Na}$ análise histológica do G1, nas falhas I exibiuse pouca formação de tecido ósseo, predominantemente trabecular, originando-se a partir das bordas e do fundo da lesão e com presença de tecido cartilaginoso. Nas reparações oriundas das bordas, a mobilização e diferenciação celular originavam-se do periósteo e, quando oriunda do fundo, os tipos celulares presentes eram provenientes das meninges, 
semelhante aos resultados das pesquisas de Takagi e Urist (1982). Nas falhas II, que receberam o enxerto esponjoso, foi visualizada discreta formação óssea do tipo trabecular com presença de túneis vasculares, superior àquela encontrada na falha anterior e mobilização celular nas imediações do carreador (Fig. 2A e 2B). Na falha II do animal $\mathrm{C}$ foi visualizada pequena área com presença de células da medula óssea, privada de vascularização, com formação de pequenos focos de tecido cartilaginoso. Nas demais falhas, a formação trabecular aumentou proporcionalmente com a quantidade de BMP utilizada.

$\mathrm{Na}$ falha VI do animal A foram observados pequenos focos de necrose no carreador e formação de tecido conjuntivo. Estes achados podem estar relacionados à ausência de vasos sangüíneos no local da necrose, pois, segundo Piermattei e Flo (1999), a necrose corresponde à porção de osso esponjoso que normalmente morre por deficiência nutricional e, para Schenk (1996), a carência de suprimento sangüíneo e de oxigênio pode alterar o código genético celular, induzindo a formação de tecido fibroso ou fibrocartilaginoso.

No G2 notou-se a presença de tecido indiferenciado, com grande número de células blásticas, sobretudo na falha I. A atividade osteoblástica visualizada, em sua maioria, provinha de "ilhas de ossificação" (origem endosteal-trabecular) localizadas no centro da falha e, semelhante a centros de ossificação, diferentemente do apresentado pelas falhas I, do grupo de sete dias.

Nas falhas II, a formação de osso novo foi mais evidente que aquelas constatadas em todas as falhas do G1. Foram observados "corações condróides", áreas de tecido ósseo com ósteons primários com formação de túneis vasculares (Fig. 2C), e presença de osso novo em maturação, com osteoclastos em atividade e acompanhados de fileiras de osteoblastos, o que caracteriza reabsorção e deposição de osso novo, respectivamente (Fig. 2D). Para as demais falhas foram observadas formações de tecido ósseo novo sobre o carreador. Este tecido novo continha osteoblastos e células indiferenciadas, que, provavelmente, originaram-se do autoenxerto e/ou foram atraídas por ação da BMP, por quimiotaxia, para o local da falha. Constatou-se que a hiperplasia de células jovens originou-se das "ilhas de ossificação", aumentando a formação e organização do tecido ósseo, assim como a quantidade de trabéculas presentes, respectivamente.

Ainda no G2, na falha II do animal A, além do preenchimento ósseo, também foi encontrado abundante tecido de granulação, intensamente vascularizado, que possivelmente forneceu células mesenquimais capazes de participar da formação óssea direta e que também serviu como plataforma para o crescimento de osso novo, conforme descreveu Rabie et al. (1996) para o carreador ideal.

Da mesma forma que Sato e Urist (1985) relataram em suas pesquisas após a implantação de BMP em falhas ósseas, o padrão de preenchimento de osso novo, encontrado no presente trabalho, desenvolveu-se, primariamente, a partir da meninge $\mathrm{e}$ posteriormente do endósteo-trabecular, com formação de "ilhas de ossificação" não conectadas à borda da falha.

Nas falhas I, do G3, foi verificada intensa mobilização de osteoblastos nas imediações das "ilhas de ossificação" e discreta migração celular advinda da meninge, permitindo formação de tecido ósseo novo, com linhas de cimentação e vasos sangüíneos evidentes (Fig. 3A). Nas falhas II notaram-se pequenos focos de tecido blástico, formação trabecular evidente e preenchimento ósseo proveniente das "ilhas de ossificação". No animal B também foi constatada uma faixa de tecido fibroso cobrindo o carreador, decorrente, provavelmente, da migração de células das fácias musculares e do periósteo localizado acima da falha.

Nas falhas III, IV e V foram observadas "ilhas de ossificação" rodeadas por células jovens, bem como a presença de tecido cartilaginoso em alguns pontos do preenchimento, confirmando os achados de Cheline et al. (2002) que afirmaram que a presença dessas "ilhas" rodeadas por células em diferenciação é um aspecto geralmente observado em sítios de implantação de BMP. 

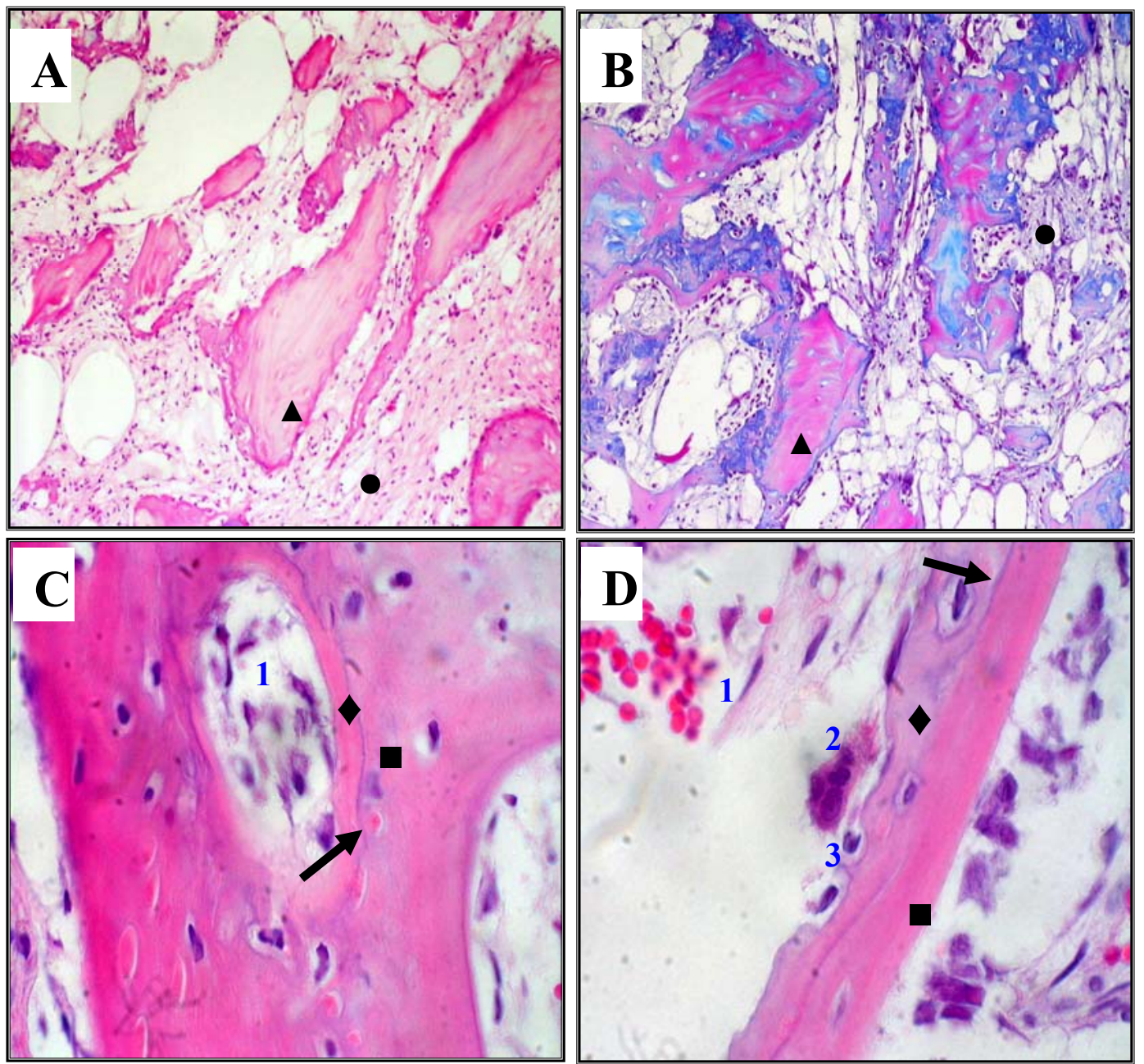

Figura 2. Aspecto microscópico do preenchimento ósseo apresentado pelos grupos 1 e 2. A) Sete dias/falha II. Mobilização celular $(\bullet)$ nas imediações do carreador $(\boldsymbol{\Lambda})$. (200x-HE). B) Sete dias/falha II. Mobilização celular $(\bullet)$ nas imediações do carreador $(\boldsymbol{\Delta})$. (200x-Masson). C) 15 dias/falha II. Formação de osso novo $(\diamond)$ acima de osso velho (ロ), com visualização de linhas de cimentação (seta), formação de túneis vasculares (1). (1000x-HE). D) 15 dias/falha II. Formação de osso novo ( $\downarrow)$ acima de osso velho (๘), com visualização de linhas de cimentação (seta), túneis vasculares (1), e osteoclastos em atividade (2), acompanhados de fileiras de osteoblastos (3), caracterizando absorção e deposição de osso novo, respectivamente. (1000x-HE).

Para as falhas VI, visualizou-se grande formação óssea trabecular, porém as células osteoblásticas que as rodeavam apresentavam-se desorganizadas. Pode-se inferir que a quantidade de BMP pode ter sido inadequada em relação à do carreador, refletindo a desorganização tecidual. Segundo Lind (1996), a BMP possui ação osteoindutora, agindo nas células osteoprogenitoras, diferenciando-as e auxiliando a osteogênese. Os resultados sugerem que o efeito desse fator de crescimento suplantou o número de receptores celulares presentes no enxerto.

No animal $\mathrm{D}$ desse grupo foi identificada a presença de mastócitos e de uma reação imunomediada inespecífica. Verificou-se que nas falhas que continham concentrações de 5; 2 e $1 \mathrm{mg}$ de BMP havia a presença de material refringente no interstício sendo fagocitado por osteoclastos e havia desorganização celular, o que sugeria haver, nessa etapa, formação trabecular óssea seguida de reabsorção estimulada por algum fator irritativo (Fig. 3B). Gerhart et al. (1993) e Cook et al. (1994) relataram reações imunomediadas associadas a não união óssea, ocasionadas pelo processamento laboratorial das formas recombinantes purificadas de BMP. Todavia, como apenas um animal do experimento manifestou intolerância, pode tratar-se de reação individual. 

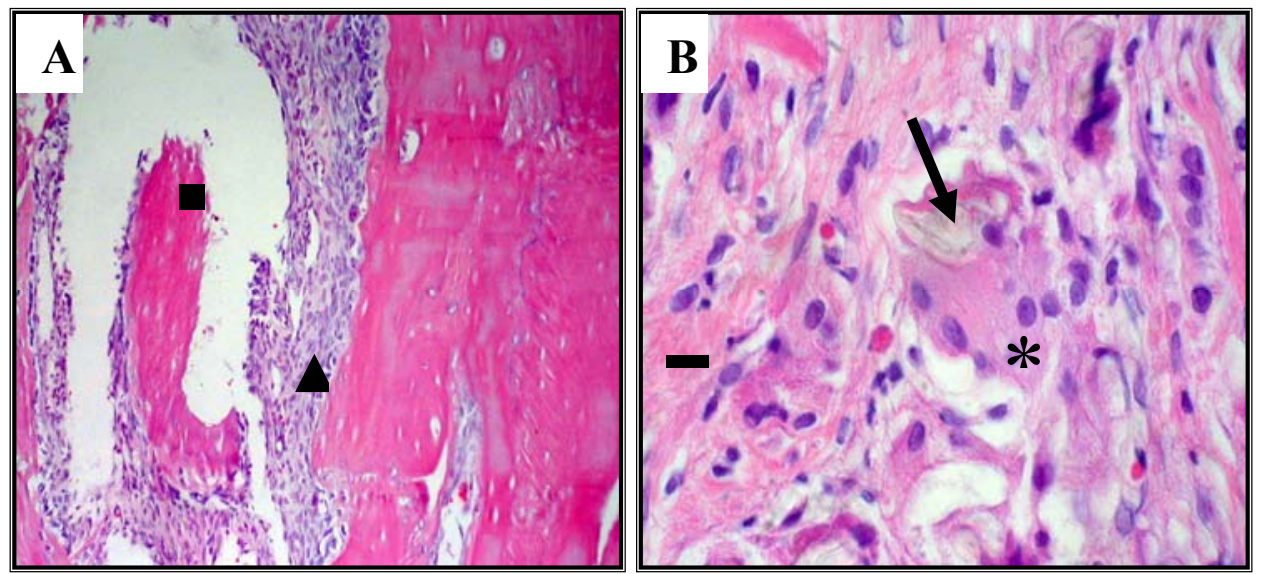

Figura 3. Aspecto microscópico do preenchimento ósseo apresentado pelo grupo 3. A) Falha I. Formação de "ilhas de ossificação" ( $\mathbf{a})$ com intensa mobilização de osteoblastos em suas imediações ( $\boldsymbol{\Delta}$ ).(200xHE). B) Falha IV do animal D que apresentou reação imunomediada inespecífica à presença de BMP. Presença de material refringente (seta) sendo fagocitado pelos osteoclastos $(*)$ e desorganização celular (一). (1000x-HE).
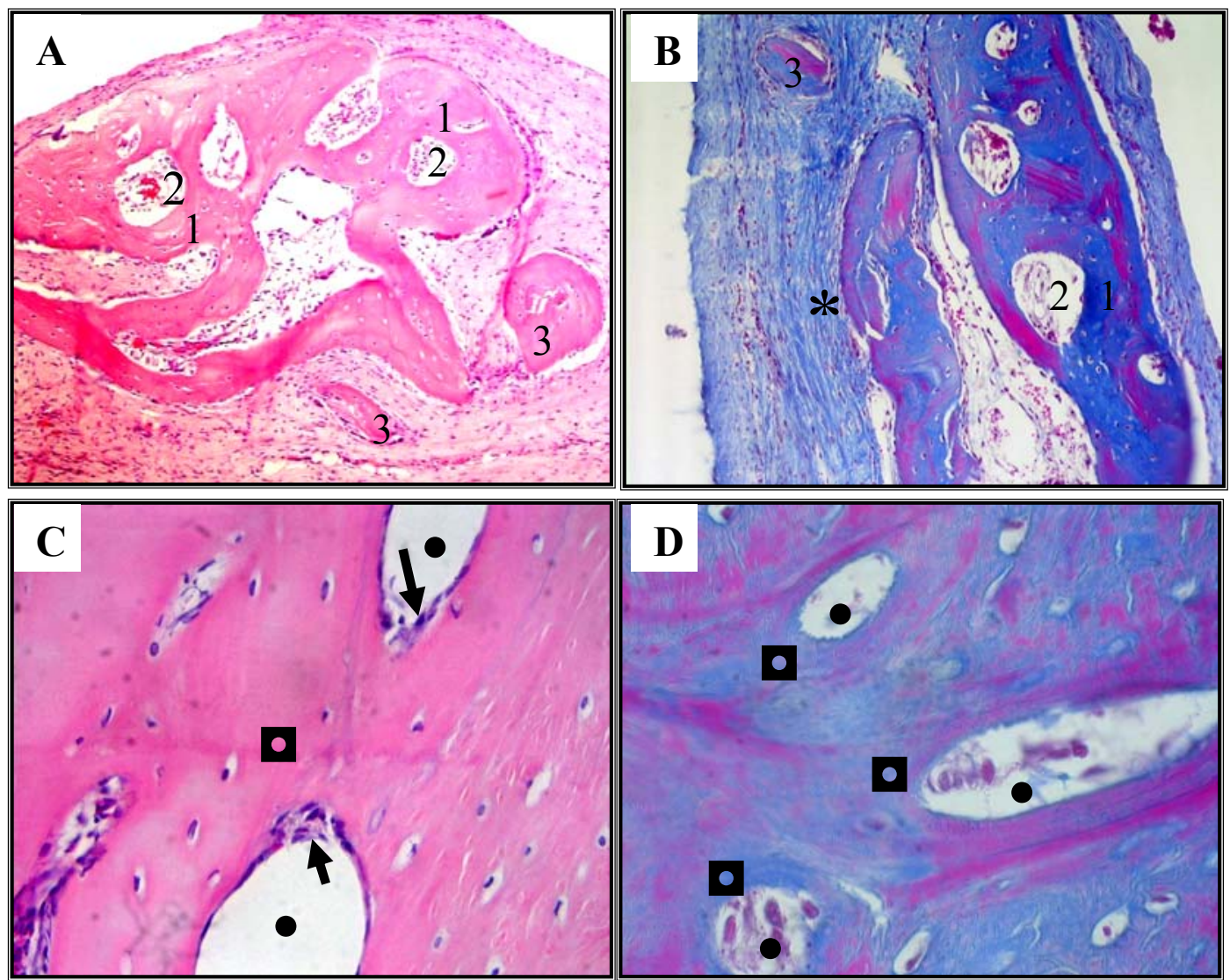

Figura 4. Aspecto microscópico do preenchimento ósseo apresentado pelos grupos 4 e 5. A) Falha IV/grupo 4. Formação de ósteons primários (1) em torno de túneis vasculares (2) e "ilhas de ossificação" (3). (100x-HE). B) Falha IV/grupo 4. Formação de ósteons primários (1) em torno de túneis vasculares (2), "ilhas de ossificação" (3) e presença de tecido fibroso (*). (200x-Masson). C) Falha V/grupo 5. Tecido ósseo maduro (ם) se organizando em torno de túneis vasculares $(\bullet)$ e visualização de fileiras de osteoblastos (setas). (1000x-HE). D) Falha V/grupo 5. Tecido ósseo maduro (a)organizando-se em torno de túneis vasculares $(\bullet)$. (1000x-Masson). 
No G4, a formação de tecido ósseo estava presente, sobretudo nas falhas que continham BMP. Nas falhas I foi observada organização e remodelação óssea, com ósteons primários, marcante presença de vasos sangüíneos, de osteoclastos e de pequenas áreas de tecido cartilaginoso. Nas falhas II, foram encontradas grandes quantidades de osso novo, diminuída quantidade de carreador, presença de muitos vasos sangüíneos e organização óssea mais avançada. A evolução da reparação e o menor volume de carreador podem ser justificados pelas observações de Marx (1994), nas quais, o reparo ósseo iniciou-se imediatamente após a colocação do enxerto e que, por volta da quarta semana após a cirurgia, o processo de substituição do enxerto esponjoso foi mais evidenciado.

Nas demais falhas preenchidas com BMP foram visualizados ósteons primários (Fig. $4 \mathrm{~A}$ e B), porém o tecido ósseo formado mostrou, em sua maior parte, a presença de ósteons secundários. Em alguns animais ainda foram encontrados restos de tecido cartilaginoso, concordando com os achados de Yasko et al. (1992) que também encontraram tecido cartilaginoso anterior à formação óssea, em todas as suas amostras experimentais, no mesmo período de observação. $\mathrm{Na}$ medida em que aumentava a concentração de BMP, constatou-se que a formação óssea era maior e a organização em ósteons secundários estava mais evidenciada, sem que fosse observado tecido cartilaginoso que, por outro lado, estava presente nas falhas I.

O tecido ósseo de reparação que cobriu as falhas estava relacionado à formação óssea por aposição, derivada das células osteogênicas presentes no local e atraídas por quimiotaxia inerente ao fator de crescimento BMP (Tsumaki e Yoshikawa, 2005). Esse tecido ósseo de reparação, também, derivou-se de mecanismo dependente de cartilagem, observada nos grupos 1, 2, 3 e 4, cujas células podem ter chegado ao local pelos túneis vasculares que se formaram ou terem sido atraídas por ação da proteína óssea morfogenética.

No G5, histologicamente, as falhas apresentavam tecido ósseo bem organizado. Nas falhas I e II, o número de ósteons foi menor do que nas falhas em que a BMP estava presente. Na falha II do animal $\mathrm{C}$, ainda existiam restos trabeculares sendo reabsorvidos. Não foi encontrado tecido cartilaginoso nas falhas, que já teria se calcificado, vascularizado e sido substituído por tecido ósseo, assim como encontraram Takagi e Urist (1982).

Aos 60 dias, a falha $\mathrm{V}$ foi a que apresentou maior organização óssea e melhor preenchimento, sendo visualizado tecido ósseo maduro que se organizava ao redor de túneis vasculares e fileiras de osteoblasto em atividade (Fig. 4C e 4D). Mas, independentemente do período de observação, o comportamento celular foi semelhante entre as falhas no mesmo animal, variando apenas a intensidade e a organização.

A formação de osso novo foi maior e mais precoce nas falhas tratadas com BMP quando comparadas com as falhas I e II, assim como observado por Springer et al. (2005). Ainda, segundo Yasko et al. (1992), o osso que se formou na presença de BMP foi histologicamente indistinguível daquele produzido quando foram utilizados enxertos ósseos autógenos, matriz óssea desmineralizada e outros substitutos ósseos, diferindo apenas quanto à precocidade de formação óssea, uma vez que essas proteínas têm o poder de induzir a quimiotaxia de células que irão participar do processo de reparação.

$\mathrm{Na}$ presente pesquisa, observou-se que nas falhas que continham BMP até a quantidade de $2 \mathrm{mg}(0,5$; $1 ; 2 \mathrm{mg}$ ), quanto maior a quantidade utilizada, maior foi o preenchimento, e as falhas $\mathrm{V}$ foram as que apresentaram maior cobertura óssea. Todavia, para a quantidade de $5 \mathrm{mg}$ de proteínas utilizada nas falhas VI, não foi observado crescimento ósseo superior às demais falhas que continham $o$ biomaterial.

\section{CONCLUSÕES}

A adição de proteínas ósseas morfogenéticas, mesmo em menor quantidade, influenciou de forma positiva, a precocidade de formação óssea. Observou-se que a maior quantidade de BMP não determinou o maior preenchimento ósseo e que os melhores resultados de preenchimento ósseo foram encontrados nas falhas onde associou-se $2 \mathrm{mg}$ de BMP a $3 \mathrm{mg}$ de enxerto. Histologicamente, comprovou-se que a BMP influencia positivamente na formação de novo tecido ósseo, promovendo maior mobilização, diferenciação, organização e remodelação celular e abrevia o tempo de formação óssea que se dá, predominantemente, por ossificação endocondral.

\section{AGRADECIMENTOS}

Ao $\mathrm{CNPq}$ - L.C.P. Pinheiro é bolsista PIBICCNPq. 


\section{REFERÊNCIAS BIBLIOGRÁFICAS}

ALLEGRINI Jr., S.; YOSHIMOTO, M.; SALLES, M.B. et al. Bone regeneration in rabbit sinus lifting associated with bovine BMP. J. Biomed. Mater. Res., v.15, p.127-131, 2004. AYRES, M.; AYRES Jr., M.; AYRES, D.L. et al. BioEstat 2.0 - aplicações estatísticas nas áreas das ciências biológicas e médicas. Brasília: Sociedade Civil Mamirauã/CNPq. 272p. 2000.

BECKER, W.; SCHENK, R.; HIGUCHI, K. et al. Variations in bone regeneration adjacent to implants augmented with barrier membranes alone or with demineralized freeze-dried bone or autologous grafts: a study in dogs. Int. J. Oral Maxillofac. Implants., v.10, p.143-154, 1995.

BRAZ, F.; RAHAL, S.C.; ROCHA, N.S. et al. Emprego de matriz óssea orgânica bovina e hidroxiapatita no reparo de defeito induzido em crânio de ratos. Acta Cir. Bras., v.18, p.19-24, 2003.

CHANG, S.C.; CHUANG, H.; CHEN, Y. et al. Cranial repair using BMP-2 gene engineered bone marrow stromal cells. $J$. Surg. Res., v.119, p.85-91, 2004.

CHELINE, A.J.; REDDI, A.H.; MARTIN, R.B. Bone morphogenetic protein-7 selectively enhances mechanically induced bone formation. Bone, v.31, p.570-574, 2002.

CIANI, R.B.; RAHAL, S.C.; VOLPI, R.S. et al. Mistura de proteínas morfogenéticas ósseas, hidroxiapatita, osso inorgânico e colágeno envolta por membrana de pericárdio no preenchimento de defeito ósseo segmentar em coelhos. Arq. Bras. Med. Vet. Zootec., v.58, p.59-67, 2006.

COOK, S.D.; BAFFES, G.C.; WOLFE, M.W. et al. Recombinant human bone morphogenetic protein-7 induces healing in a canine long-bone segmental defect model. Clin. Orthop. Relat. Res., v.301, p.302-312, 1994.

DEL CARLO, R.J.; IAMAGUTI, P.; BRANCO, M.D.L. et al. Cranioplastia por interposição de auto-enxerto costal. III. Aspectos da enxertia óssea. Arq. Bras. Med. Vet. Zootec., v. 46, p. 244-252, 1994.

ELLIS, E.; SINN, D.P. Use of homologous bone in maxillofacial surgery. J. Oral Maxillof. Surg., v.51, p.1811193, 1993.

GERHART, T.N.; KIRKER-HEAD, C.A.; KRIZ, M.J. et al. Healing of large mid-femoral segmental defects in sheep using recombinant human bone morphogenetic protein (BMP-2). Clin. Orthop. Relat. Res., n.293, p.317-326, 1993.

KUBOKI, Y.; SAITO, T.; MURATA, M. et al. Two distinctive BMP carriers induce zonal chondrogenesis and membranous ossification, respectively; geometrical factors of matrices for cell-differentiation. Connect. Tissue Res., v.32, p.219-226, 1995 .

LIND, M. Growth factors: possible new clinical tools. A review. Acta Orthop. Scand., v.67, p.407-417, 1996.

MARX, R.E. Clinical applications of bone biology to mandibular and maxillary reconstruction. Clin. Plast. Surg., v.21, p.377-392, 1994.

MARUKAWA, E.; ASAHINA, I.; ODA, M. et al. Bone regeneration using recombinant human bone morphogenetic protein-2 (rhBMP-2) in alveolar defects of primate mandibles. Br. J. Oral Maxillof. Surg., v.39, p.452-459, 2001.

OLESKOVICZ, C.; LISAUSKAS, S.; ARAGÃO, F.J.L. Expression of human bone morphogenetic protein (BMP-2 and BMP-4) genes in transgenic bovine fibroblasts. Arq. Bras. Med. Vet. Zootec., v.56, p.547-549, 2004

PIATTELLI, A.; SCARANO, A.; PIATTELLI, M. Microscopic and histochemical evaluation of demineralized freeze-dried bone allograft in association with implant placement: a case report. Int. J. Periodont. Res. Dent., v.18, p.355-361, 1998.

PIERMATTEI, D.L.; FLO, G.L. Enxertos ósseos. In: Manual de ortopedia e tratamento das fraturas dos pequenos animais. São Paulo: Manole, 1999. p.139-145.

RABIE，A.B.; DAN，Z.; SAMMAN，N. Ultrastructural identification of cells involved in the healing of intramembranous and endochondral bones. Int. J. Oral Maxillofac. Surg., v.25, p.383-388, 1996.

RUTHERFORD, R.B.; WHALE, J.; TUCKER, M. et al. Induction of reparative dentine formation in monkeys by recombinant human osteogenic protein-1. Arch. Oral Biol., v.38, p. 571-576, 1993.

SAKOU, T. Bone morphogenetic proteins: from basic studies to clinical approaches. Bone, v.22, p.591-603, 1998.

SATO, K.; URIST, M.R. Induced regeneration of calvaria by bone morphogenetic protein (BMP) in dogs. Clin. Orthop. Relat. Res., v.197, p.301-311, 1985.

SCHENK, R.K. Regeneração óssea: bases biológicas. In: BUSER, D.; DAHLIN, C.; SCHENK, R.K. Regeneração óssea guiada na implantodontia. São Paulo: Quintessence, 1996. p.49-100.

SOMMERMAN, M.J.; HEWITT, A.T.; VARNER, H.H. et al. Identification of bone matrix derived chemotatic factor. Calcif. Tissue Int., v.35, p.481-485, 1983.

SPRINGER, I.N.G.; AÇIL, Y.; KUCHENBECKER, S. et al. Bone graft versus BMP-7 in a critical size defect-cranioplasty in a growing infant model. Bone, v.37, p. 563-569 2005.

TSUMAKI, N.; YOSHIKAWA, H. The role of bone morphogenetic proteins in endochondral bone formation. Cytok. Growth Factor Rev., v.16, p.279-285, 2005.

TAKAGI, K.; URIST, M.R. The reaction of the dura to bone morphogenetic protein (BMP) in repair of skull defects. Ann. Surg., v.196, p.100-109, 1982.

URIST, M.R.; DELANGE, R.J.; FINERMAN, G.A.M. Bone cell differentiation and growth factors. Science, v.13, p.680686, 1983.

WAN, M.; CAO, X. BMP signaling in skeletal development. Biochem. Biophys. Res. Commun., v.328, p.651-657, 2005.

YASKO, A.W.; LANE, J.M.; FELLINGER, E.J. et al. The healing of segmental bone defects, induced by recombinant human bone morphogenetic protein (rhBMP-2) - a radiographic, histological, and biomechanical study in rats. $J$. Bone Joint Surg., v.74(A), p. 659-670, 1992. 